\title{
A Psychospiritual Exploration of the Transpersonal Self as the Ground of Healing
}

\author{
Monique M. Verrier
}

check for updates

Citation: Verrier, Monique M. 2021. A Psychospiritual Exploration of the Transpersonal Self as the Ground of Healing. Religions 12: 725. https:// doi.org/10.3390/rel12090725

Academic Editors:

Bernadette Flanagan and

Noelia Molina

Received: 10 August 2021

Accepted: 31 August 2021

Published: 5 September 2021

Publisher's Note: MDPI stays neutral with regard to jurisdictional claims in published maps and institutional affiliations.

Copyright: (C) 2021 by the author. Licensee MDPI, Basel, Switzerland. This article is an open access article distributed under the terms and conditions of the Creative Commons Attribution (CC BY) license (https:// creativecommons.org/licenses/by/ $4.0 /)$.
Holistic Counseling in Psychology, John F. Kennedy School of Psychology, National University, Pleasant Hill, CA 94523, USA; moniqueverriertherapy@gmail.com or mverrier@email.jfku.edu

\begin{abstract}
This paper focuses on the transpersonal Self as the psychological and spiritual healing factor in psychotherapy and addiction recovery, and illustrates the importance of bringing awareness of the Self and the energy of wholeness into focus with clients in the therapeutic process. The concept and experience of Self is explored through the psychospiritual therapeutic model of Internal Family Systems and through a spiritual lens of the nondual wisdom traditions derived from Advaita Vedanta and aspects of Kashmir Shaivism. Obstacles to the recognition of Self, approaches to facilitating this recognition, and the therapeutic benefits of knowing the essential Self are examined through the author's personal experience with these models and their use in overcoming depression, anxiety, eating disorders and addiction. Psychotherapeutic interventions that support making contact with the Self are examined as well as the implications of Self-knowing on personal relationships, behavior and inner experiences, as well as how one relates to others and the world.
\end{abstract}

Keywords: addictions; eating disorders; existential psychology; healing; Internal Family Systems; nonduality; psychotherapy; transpersonal psychotherapy

\section{Introduction}

Many psychotherapeutic models, such as the psychoanalytic, psychodynamic, behavioral and cognitive approaches, are either explicitly or implicitly rooted in an assumption that the cause of psychological pathology and dysfunction is some kind of lack: of development, growth, self-esteem, confidence, trust, self-love, emotional regulation, positive thoughts, impulse control, etc. I offer here an alternative perspective that people innately possess all the qualities and inner resources they need for total mental and spiritual health no matter what their psychological background or experience. We do not become whole, we are whole. We are wholeness veiled by the addition of psychological constructs and beliefs that seem to obscure this truth, including the very belief that we are lacking or not whole. A therapist's or counselor's understanding from this perspective may minimize the possibility of unintentional reinforcement of beliefs and self-constructs around the sense of lack that further contributes to the obscuring of Self as wholeness for clients. This orientation supports clients' recognition of the transpersonal, essential Self right now, and deepens that knowledge of Self into firm inner grounding, supporting what might otherwise be a challenging healing process by promoting innate safety and relaxing psychological ego defenses.

The path to knowing the Self is varied but often starts with a divesting of what is not essential to our Being. It is a path of subtraction, unburdening, and uncovering. A curious phenomenon occurs in this process of divesting, which is that we fall deeper into an ever-widening circle of Self that is paradoxically more inclusive of experience. In this lessening, we become more expansive and the freedom to be our unique person occurs gently and effortlessly. It is the impersonal path of Self to the deepest and most intimate personal expression of who we are.

Through direct and skilled guidance, we can come to know the nature of ourselves as wholeness, having both immediate and gradual effects. The touching into our Being is 
direct and yet gradually deepens and transforms from the inside out. Knowing our Self is ordinary, ever present, and yet often overlooked. For this reason, client Self-led counseling might also be an overlooked therapeutic approach that could help soften defenses and increase security from a grounded base. There is a common misunderstanding that it takes years of ego building or exploring personality traits before we can really know ourselves. However, everyone knows themselves. Our Self is what we all refer to when we say ' $\mathrm{I}$ ', but we rarely explore the nature of that ' $\mathrm{I}$ ' (Spira 2017a). This paper will explore the nature of Self through a psychotherapeutic model with a spiritual lens, Internal Family Systems (Schwartz and Sweezy 2020), and through the spiritual model of the nondual wisdom, explored through a psychological lens. In both these models, the awareness of Self is established as the primary ground upon which further self-exploration and healing grows. I acknowledge that there are myriad theories on the nature of Self, Jungian theory being chief among them, and thus my analysis here is necessarily selective as it is beyond the scope of this paper to address them all (for an overview of different approaches to Self the reader is referred to Daniels 2002a, 2002b). I share my own experience in psychotherapy and spiritual exploration as a way of showing the power of conscious awareness of our essential Self to liberate oneself from the maze of the mind and psychological suffering that often underpins addiction and compulsive behaviors.

The following account of my personal experience is what I found to be valuable in my healing and may not be the appropriate path for others. It requires a certain amount of willingness and capacity to explore the self in a transpersonal way. Medical support and addressing environmental deficiencies may also be required. In the exploration of my experience, my hope is to bring to light the unintentional ways that counselors might reinforce and perpetuate their clients' identification with core beliefs of brokenness, defectiveness, unacceptableness, and separation. Uncovering the ever-present, never broken, whole aspect of Being and bringing it to the light of awareness and into the therapy or recovery process can facilitate the healing of those aspects of ourselves that are lost, hurt, confused and in need of connection. The alchemy of healing occurs when that which can never be harmed makes contact with that which can, revealing that what appears to be shadow is really those apparent aspects of ourselves that seem to block the light of our being. Certain terms and words will be used in specific ways. For a list of definitions, the reader may refer to Appendix A.

\section{The Whole Story: A Psychotherapy Journey}

I started psychotherapy at age 11 at my own request due to a deep depression. My initiating therapy at that age points starkly to the unresolved inner conflict that continued for more than 30 years: the subtle core belief that there is something wrong with me or something fundamentally missing and the equally hidden yet unrelenting conviction that this, in fact, cannot be true. Somewhere deep inside me I knew that there was something wrong, and I also knew as well that the idea of 'something wrong' was wrong and that I needed help connecting to what I knew was true. I was not able to articulate or explain these feelings at the time and this is only something that I can reflect on half a lifetime later. All I knew then was that something was not right and that I had a desperate longing for something I could not pinpoint or define. It was only many years later that I understood this feeling as a longing for myself, the nature of which is life itself.

The beginning of my work with the Jungian Analyst who was to be my therapist for over 30 years started with minutes-long silences whereby I had the undivided attention of a caring and attentive person. The silences were punctuated with 'what are you feeling?'something I perceived as a trick question and one that I loathed and for which 'fine' was always the answer. This was my first experience with the Jungian style of leaving wide open spaces for 'something' to emerge. When I discovered the sand tray, I was relieved, as that was my way out of the 'what are you feeling?' situation. My sand tray pictures spoke for me. 
Fast forward a few years...I was definitely in touch with my feelings and I had a much better understanding of what happened to me in my family. However, my mind had become a mouse in a maze of circular thoughts scurrying around confusing tight spaces and dead ends. I had become very depressed and anxious, something that would only get worse throughout my teenage years and early adulthood. An eating disorder that started as a child grew in severity, and by the time I was 15 , I was exhibiting alcohol abuse. By my early twenties, I was on the path toward alcoholism. My self-esteem was very low, I had painful ruminating thoughts, and I completely seized on these negative ideas running rampant in my mind. The only solution to these painful experiences was food, and later, alcohol. Each time I delved into the reasons for my behavior, I came up with the same answer: I must be damaged or weak, simply incapable of handling life. My mind became a murky pond. When I finally found my way through it, I felt like my head had finally popped above the dark water and I could see and breathe again. That would not be until 31 years after the start of my therapy.

\subsection{A Maze of the Mind or a Labyrinth of the Soul}

In Awakening the Heart: East/West Approaches to Psychotherapy and the Healing Relationship (Welwood 1983), Thomas Hora tells the story of a man who had been in analysis for several years due to his problem of nail biting. When asked by a friend how the analysis was going, he proclaimed it was 'wonderful.' When asked if he had stopped biting his nails, he answered, "No, but now I know why I do it" (Hora, in Welwood 1983, p. 132). This was exactly my experience. I could have written volumes on why I did what I did, but I was still doing it, which added to my suffering. Now I 'knew better' but I was not 'doing better.' I could see all the psychological threads but was hopelessly entangled in them. I saw how my psychological self was put together, but as I still identified with this self, I felt destined to live out this painful conditioned patterning, since it seemed like 'me.' Ram Dass points out,

Psychotherapy, as defined and practiced by people like Erikson, Maslow, Perls, Rogers, the neo-Freudians, or the neo-Jungians does not in the ultimate sense transcend the nature of ego structure. They really seem to be focused on developing a functional ego structure with which you can cope effectively and adequately with the existing structure. They have very little to say about how deeply identified you are with the ego structure.

(Ram Dass in Welwood 1983, p. 34)

After years of therapy, I was functional within my culture; had a grasp on reality; knew myself as a distinct person; performed well enough at my job despite the constant anxiety; and could tolerate basic emotions. I had done a good job of figuring out the maze and had worked out how to manage some of the trickier parts and dead ends. However, internally, I was deeply confused and suffering. Conceptual pathways to healing that I discovered along the way, such as redemption, self-empowerment/self-esteem building, self-actualization, and transformation sometimes added to my burden. I utterly failed at these 'tasks' and that added more to my conviction that I was just simply broken beyond hope. By age 33, my eating disorder had taken to riding in the sidecar of alcoholism and despite the antidepressants I had been taking for 10 years, I still suffered from depression and had anxiety around even the smallest life pressure. I lived my life as safely as possible to mitigate my fear. I had done a lot of work in therapy-uncovering repressed emotions, understanding my role in my family and examined extensively the deficiencies in my early environment. I had mourned the mother I needed but never had, felt compassion for the lost, vague little girl I once was, and pieced together the story of me. Yet, I suffered to the point of despair.

I figured there must be more to know, more to discover, some secret repressed in my subconscious that once brought to consciousness would hold the answer to my healing. I did not realize through all those years that my assumption of and identification with a psychological conditioned self, a self-image or ego, was setting me on a path of identifying 
with an image of brokenness, of not being adequate. In the search for the fix, I was inadvertently reinforcing the idea that my very self was broken or damaged. It had not yet occurred to me that, although thoughts can be disturbing, feelings can be painful and hurtful, there was no hurt or disturbed self to be found. When I finally turned inward to look for this broken person, all I found were mutable thoughts, images, memories, and feelings-all contributing to a sense of self, but no broken, damaged person could be found. In The Paths of Ego (Welwood 1983), Hora quotes a French psychiatrist who says, (translated to English), "We don't get well because we remember, but we remember as we get well" (p. 133). Getting well, for me, meant exploring the truth of my own existence, my own Being, before I could go any further in uncovering my past. In order to begin healing beyond general emotional stability, I did not necessarily need a big understanding of the meaning of life, I just needed to peek around the edges of who I understood myself to be, and in order to do that, I needed to ask the right questions. In discussing existential psychotherapy, Hora (Welwood 1983) explains that we do not probe the past, " ... we allow it to reveal itself in the course of gaining a better understanding of what is" (p. 134). I felt the pain of probing the past without the proper understanding of 'what is' in broader terms and this was causing more harm than good after a while. Hora goes on to say that (in existential psychology) we do not ask 'Why?' and we do not ask 'Who is to blame?' or 'What should I do?' I came to see that these types of questions are asked from the perspective of the self who feels broken and needs to be fixed. The answers led me deep into stories of resentment, self-pity and failed therapy strategies to fix a deficient self, leading to more despair for which the only remedy was more alcohol. The failure of the broken self to heal the broken self reaffirmed the belief in a broken self. What I was truly craving was a deep understanding of what Hora calls 'what is' as it relates to the nature of being and truth that aligned with my actual experience in the background of the depression.

In my persistence to not fall into a black hole and to overcome my addictions, I analyzed every dream and symbol, probed for memories, tried countless types of therapeutic interventions and recovery methods, all giving me a temporary sense of direction and control that provided a double-edged sword: a sense of hope-the carrot that I would chase for more than 30 years-and then despair. Even my anti-strategy strategies of 'letting go,' 'giving over' or 'surrender' were approached with an effortful doing. There was always a 'me' that needed to 'do' the surrendering, the letting go. I had not yet understood that what needed to be surrendered was me, or who I thought myself to be, and that letting go

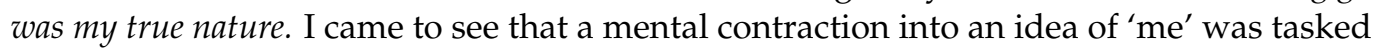
with 'letting go' and this mental activity, in turn, created a sense of self that was then further identified with. Later, it became clear that my default is letting go and all efforts to let go only add to that which seems to need to be let go of. A clever little trap.

Hora (Welwood 1983) goes on to say that in existential therapy, mainly, we ask two questions: 'What is the meaning of what seems to be?' and 'What is what really is?' What really started healing on a deep level was posing the implicit questions 'what seems to be?' and 'what really is?' What does the world and self appear to be and what is the reality of the world and who I am? In analysis, I had ferreted out all the psychological patterns. I had identified the letters and recognized the patterns of words and had seen the sentence that was my story and truly felt its emotional impact. However, the sentence was utterly out of any broader context. It meant nothing on its own-a dangling incomplete sentence of 'me' that I stared at and tried to make sense of for decades. It did not occur to me that the person who was trying to make sense of it was actually one of the words in the sentence-a word not seeing itself as a word and not realizing that the missing word that rendered the sentence nonsensical was simply the fact of not seeing who I thought of as myself as one of the words-in other words, a part of the story. From that word's point of view, there was always going to be something missing from that sentence because the word (the identified self) was embedded in the story. 
Many years later, I realized that what I was longing and searching for was that which is essential to me within a larger context and that nothing I tried to see from the vantage point of that which was generated from within the story, stemming from a misunderstanding about who I was, would ever be capable of seeing what is. The confusion I felt exemplified the issue that the contemporary nondual teacher Rupert Spira (2017b) raises: “The mind cannot know the nature of reality until it knows its own nature" (p. 27) and from this standpoint, the sentence of 'me' was never going to make sense from the perspective of one of the words in the sentence. Spira (2017b) further explains that knowing the nature of mind does not mean to study the content of the mind, but rather to discover the essential nature of the mind. What I had not yet seen was that the words in the sentence change, and what is constant is the space in between the words, that which is essentially me. What I had yet to discover was that with a broader perspective, the maze of my mind could become a labyrinth of liberation - a single windy path to the center of my Being. One path in and the same path out.

\section{A Mental Maze Becomes a Labyrinth of Liberation}

I finally realized that the maze of my mind was entirely thought-created, consisting of memories, judgements, worries, interpretations, predictions and expectations, all circling around a felt concept of ' $\mathrm{me}^{\text {', }}$ which was then tasked with various means to solve itself. Mazes are multicursive and branchlike, causing the follower to choose between different paths in order to reach some destiny or goal. Some of these paths lead to dead ends and turnarounds, causing the follower to go in circles (Kingsley 2010). There are several ways in and out. In order to 'solve' a maze, more thought is created-more 'figuring out,' learning, memory, and finding patterns. As an analogy of mental and emotional processes, it is easy to see how the maze can seem never ending. It seemed that the more I tried to understand the maze, the deeper and more complicated it became. Trying to solve it seemed to somehow create more of it.

I now see this process that I associate with the maze as an occurrence within a larger and more profound journey: that of the labyrinth. The objectives of a maze are very different from that of a labyrinth. Solving a maze involves making sense of experiences, learning details particular to that part of the maze, and makes use of memory and future projection. I see the labyrinth as related to what is, and is not so much something we do but is simply what is happening. The experience of the maze for me now seems like an abundance of activity undertaken while, in actuality, I was slowly moving forward in the labyrinth toward a deeper understanding of the Self. The labyrinth path may seemingly lead further away from the center (in this case, the knowing of Self) and then fold towards it again in twists and turns, but the path is unicursive, so the only choice is forward toward the center or away, back toward the single entrance/exit. In explaining the history of mazes and labyrinths in art, and the interpretive difference between a maze and a labyrinth, Kingsley explains, "The labyrinth is regarded as a more solemn undertaking [than the maze] associated with ritual and spiritual and religious journeys" (Kingsley 2010, p. 90). For me, what initiated the change from a mental maze to a spiritual path was turning toward my thoughts with curiosity and openness. As the nondual teacher and psychologist, Dr. Gail Brenner (2018), suggests, "Instead of swirling in the content of the thoughts, you open up to seeing them with wisdom and clarity" by relaxing attention "away from involvement into the safe haven of being aware" (p. 92). It was this small shift in focus toward the Self beyond the ego that fundamentally changed my course.

The beginning of my discovery of the transpersonal Self and the primacy, constancy, and eternal quality of the essential nature of myself started with a feeling and an image that came to me during a meditation in which I sensed the ever-changing nature of everything and all experiences: pets, friends and partners who had come and gone; various homes, the changing cells in my body, ideas, feelings-all of it was sensed as flowing through and around a golden thread that was strong, constant and seemed to have no beginning or end. This golden thread started before the story of 'me' and I simply knew it would still be 
present after my body and mind ceased to be, yet I knew also that this thread was me-an immutable Self. That was the first time ever in my life that I knew that I could handle all change, that the death of my loved ones, or any loss, while painful and difficult, could not take anything essential from me or damage or diminish me in any way. I had never felt this way before but the certainty has grown ever since.

It was years later, upon hearing the myth of Ariadne (GreekMythology.com 2021) and the golden thread that she gives to Theseus in order to find his way out of the labyrinth and back to her (his true love) as he journeyed to the center to slay the minotaur, that both the images of the golden thread and the labyrinth made sense to me. I have come to see the thread as the constant and ever-present essence of Being on the one path that can only ever lead back to our Self-our true heart. What changed my experience of the maze of my mind into a labyrinth of liberation was a loosening of focus on the mutable inner and outer objects of experience and a curiosity in and growing awareness of the golden thread that weaves through all of it. At the time I was in Jungian therapy, this wider scope of life, this labyrinth that I had not yet come to see as my own Self, I had known only esoterically as a spiritual path, a religion, a philosophy, a self in which I might be a fragment of the collective unconscious that I may have access to (again, from beyond myself). From my own perception, Jung's ([1954] 1970) concept of individuation, which he believed usually started around mid-life, perhaps is what I contributed to this Self, but it was something that I had known as a child, and is perhaps more in line with what some other cultures have described as the essence of life, Buddhahood, or other known applications of such a term. Once I was able to name it, I knew it for what it had always been in my life and the concepts of mythology that I had learned in Jungian therapy helped me see this path through this labyrinth path.

The path of the labyrinth to the center of Self brought me from a life of depression, fear, and addiction to a life of joy and love of life. I no longer take the antidepressants that I was told by the medical community that I would probably need for life. Anxiety is an old friend that visits from time to time, but I feel a security that is not dependent on circumstances and a groundedness that is not created but rather simply present. I no longer suffer from alcoholism or eating disorders. Intimate relationships and close friendships feel safe. I have a broad range of emotions and an acute sensitivity, but I feel in the flow of life and have an intimacy with all of my experience.

\subsection{Longing for Self: Finding the Center of the Labyrinth}

As someone deeply interested in human experience, during this journey, I spent a lot of time reflecting on what helped me and what might help others who are stuck in the maze of the psychological self. What I came to see was that my seemingly fragmented psyche consisted of splits or aspects of a self that together formed a psychological system (Schwartz and Sweezy 2020; Fisher 2017); I completely identified this system as 'me' and therefore was unavailable to be present with the psychological system as an experience (Fisher 2017); I suffered from a belief that I was separate from the world and others that formed an existential wound - the sense that I was bound to the limitations and destiny of temporary body and finite mind. All of these together created and maintained the sense of a separate inside self that was apart from and fearful of the outside world. This insecurity required some kind of anchoring in a world of apparent objects (Spira 2016a), which took root in addictions, and at other times, relationships. It became apparent that persistent thought (mental processes), reinforced by a felt sense in the body, created this overall sense of separation and the fragmented psyche resulted from this same body-mind process that gave rise to the assumption of an inner 'separate self.' I was unaware of and completely unidentified with any aspect of myself beyond this sense of a separate self and the psychological system that developed to maintain it.

In essence, I was unaware of what I have come to see as my transpersonal Self or what I call True Nature- the self beyond the contents of mind or experience. I had become lost and identified with these psychological parts of myself consisting of emotional memory, 
images, and thoughts, and therefore had no ground upon which to stand in order to do any meaningful therapeutic work. The present Self became veiled by the superimposition of 'past' self-stories, sensed through thought, memory and sensations. Janina Fisher (2017) describes this as "having no vantage point in the here and now from which to look back and view what happened 'then'"' (p. 40). My experience is that the transpersonal Self is only here and now and therefore presence is what was required for healing.

\subsubsection{The Path of Unbecoming}

By the time I arrived at my second therapist's office, I was emotionally exhausted by my self-inflicted wanderings in the maze, which had itself become addiction like, as the compulsion to 'heal' or resolve my psychological conflicts overwhelmed me. The presence of and relationship with my childhood therapist had an immeasurable impact on my healing, but the many years of ego building 'failures' had left me worn. The relationship with my second therapist began the journey of "being" instead of "searching" or "doing". This was a process not of becoming someone but one of unbecoming. Rather than searching for myself and shining a laser beam on unconscious material, all that was required was playful curiosity and a soft relaxed mental focus. This soft focus is what I have likened to an inner version of the yogic gaze or drishti (Life 2007)—a soft but prolonged, continuous, single-pointed focus on an inner point that is stable and unmoving - what I later recognized as my essential Self. Gently focusing on this immutable part of me allowed me to find an internal anchor independent of experiences that come and go.

\subsubsection{The Healing Factors}

From this vantage point, I see that a process unfolded that facilitated healing psyche and spirit. The stages of this process prepared the ground for further healing by touching into what is essentially me and discerning what aspects are not essential to my Being. While sensing into the essential Self, I turned toward what I had previously identified as me to welcome it into a new relationship and integrate it by taking it into my Being. Eventually, I allowed this new way of being to realign my thoughts, feelings, relationships and activities. I continue to cultivate mindfulness of the habitual thinking, beliefs, and mental processes that create an apparent veiling of my Self, and which reinforces the identification with a separate insecure self.

This therapeutic approach embraces a clear and direct path to knowing the Self, and from that perspective, progressively realigns, reorients, restructures, and facilitates the processing of old conditioning and feelings, especially the ones rooted deep in the body, by attending to those painful beliefs and feelings. This essentially flips the usual psychotherapy process around whereby we explore what is essentially true first and then from that grounding, sorting through and seeking to make sense of that which appears to be true. I found that what impeded so much of my previous efforts to heal was that I simply could not fully process or integrate 'what appears to be true' from the vantage point of 'what appears to be true.' In other words, most psychotherapy will focus on the client's associations, meaning making, interpretations, and beliefs around the psychologically constructed self-all of which appears true to the client from the perspective of the constructed self-and neglect or ignore what is always true in our experience; all that is not dependent on circumstances, a particular perspective, mind set or beliefs.

Therapeutic attempts to 'resource' a client often miss the most fundamental and always available resource: the immutable presence of Being or transpersonal Self. In my inquiries into why this is so, I have come to understand that either this essential Self is not known by the counselor or therapist or they do not know how to help clients come to see this ever-present Self in their immediate experience. One focus of this paper is to explore approaches to psychological and spiritual healing that acknowledge the Self as the healing factor in psychotherapy and approaches to bring this Self or the energy of Wholeness into focus with clients early in the therapeutic process. 


\section{Theoretical Models for Self-Exploration: Internal Family Systems and Nondual Wisdom}

Some models of psychotherapy and psychospiritual healing and addiction recovery models are built upon the concept or understanding of the Self, higher self, higher power, essential self, or true nature, among its many names. This section explores the psychospiritual therapeutic model of Internal Family Systems (Schwartz and Sweezy 2020) and a combination of the spiritual traditions of the Direct Method or Path (Atmananda Krishna Menon 2009), from the eastern nondual wisdom of Advaita Vedanta, and aspects of Kashmir Shaivism, as two possible approaches that might help clients recognize the Self, as it helped me in my recovery. These are often referred to as the inward and outward-facing paths, respectively, as taught by spiritual teacher Rupert Spira (2017a), which also has a background in the spiritual teachings of Francis Lucille (2006) and Jean Klein (2006). We will also look at how some psychotherapists have integrated nondual wisdom into their therapy practice. For simplicity, henceforward, Internal Family Systems will be referred to as IFS and the Advaita Vedanta and Kashmir Shaivism traditions from the perspective of the teachers and authors mentioned will be referred to as the nondual understanding or nondual wisdom. As the focus is a discussion on the healing factor of the transpersonal Self, this will not be an exhaustive theoretical discussion of the two psychological and spiritual models through which the Self is explored-Internal Family Systems and spiritual nondual wisdom-but a brief description is necessary to understand the approaches to accessing, healing and living from the Self.

\subsection{Internal Family Systems}

While many psychotherapy approaches make no mention of a self beyond a psychologically, culturally or socially constructed one, one approach in particular, Internal Family Systems, turns attention toward a transpersonal self, and in fact, derives all therapeutic benefit from the standpoint of this often-overlooked Self (Schwartz and Sweezy 2020). The IFS model brings traditional systems thinking-a mental model that promotes the idea that the component parts of a system will act differently when isolated from its environment or other parts of the system (Weinberg 2001) —into the inner psychological realm and conceptualizes and relates to individuals as human systems that make use of "structure, boundaries, positive and negative feedback, homeostasis, and degrees of embeddedness and constraint" that work within principles of "balance, harmony, leadership and development" (Schwartz and Sweezy 2020, p. 26) with which one can assess a human system.

IFS therapy is a mindfulness-based approach to understanding the psychological system that synthesizes two main paradigms: the idea of the plural mind-that we consist of many different psychological parts-and a human systems model, inviting therapists and clients to relate to all levels of the human system. IFS's approach is non-pathologizing, viewing individuals through a holistic and humanistic lens, and seeing people as innately having all the resources they need, rather than consisting of a collection of deficits or having disease. A basic premise of IFS is that "people have an innate drive toward and wisdom about their own health" (Schwartz and Sweezy 2020, p. 26) and it follows that when people are having chronic problems, they are constrained from using their innate resources and strengths due to imbalances, polarization of inner psychological parts of themselves, problems with Self leadership or burdened development as a result of trauma (Schwartz and Sweezy 2020). This 'inner system' consists mostly of unconscious desires, distortions, and agendas called "parts," which can be differentiated from the Self, the seat of consciousness, an "entity that is described and approached in many different ways in spiritual traditions around the world" (Schwartz and Falconer 2017, p. 44) and is characterized by qualities such as presence, clarity, calm and curiosity (Schwartz and Sweezy 2020).

'Parts' are autonomous mental systems within the psychic system that are like subpersonalities with their own abilities, desires, views and range of emotions. From the IFS perspective, every person contains an inner tribe of people that take on extreme roles, 
or burdens, and who, if released from these roles by a process known as 'unburdening' are likely to discover their full potential (Schwartz and Sweezy 2020). The IFS system consists of parts (subpersonalities) of the individual, that include: Exiles-parts who have been exploited, rejected/abandoned in external relationships and then judged by other parts of the system; Manager parts, who fear the extremity of Exiles and 'lock them up' by employing various strategies to keep them out awareness; and Firefighter parts who are the system's last defense, called upon when Exiles get through the defenses of the Managers and they employ extreme behavior to distract from or suppress the Exile's emotional reactions, which can include addictions or abuse of all kinds including extreme behavior such as self-cutting or stealing (Schwartz and Sweezy 2020).

While everyone has these subpersonalities, Janina Fisher (2017), who uses the IFS model extensively in her work with trauma survivors, describes the brain's innate capacity to split or compartmentalize (fragment) as an ingenious adaptive response to abuse and neglect. In order to survive and maintain some sense of ourselves as 'good,' we reject the abused self as bad and identify it as 'not me' or the Exile (Fisher 2017). This splitting and self-hatred continue long after the traumatic event is over and, while fulfilling the purpose of surviving and adapting to intolerable circumstances, it comes at the cost of "disowning their most vulnerable and wounded selves" (Fisher 2017, p. 19). To ensure this continued dissociation, other parts, the Managers and Firefighters, come into the intrapsychic world, and together, these often-polarized parts form the ecology of the inner system (Schwartz and Sweezy 2020). The Self is independent of the subpersonalities, or the system, and does not hold an extreme position. Fisher (2017) explains that "Self refers to innate qualities possessed by all human beings in undamaged form no matter how much trauma or abuse they have experienced" (p. 8), which include creativity, courage, calm, clarity, confidence and commitment. Healing in IFS is the outcome of discovering these innate qualities as an antidote to the painful experiences suffered by exiled child parts. This healing comes through in what IFS calls "Self leadership"- a process by which those with access to the Self are able to help the parts unburden by listening, understanding and being present with their parts (Schwartz and Sweezy 2020).

The contribution of IFS to my own healing and to the field of psychology is considerable. The therapeutic benefit is mostly dependent on the client's 'access' to Self, and, as such, one of the potential deficiencies of this approach is the possibility that a client might not be able to unblend or separate out these psychological parts from the transpersonal Self in order to engage in Self leadership and to benefit from this modality. For this reason, a spiritual approach borrowing from the nondual wisdom traditions can complement this modality, both in the beginning, as one turns attention toward that which is essential to oneself, and toward the end, when the psychological ego construct is integrated into the wholeness of Being.

\subsection{The Nondual Inward-and Outward-Facing Paths and the Original Split}

Some spiritual and religious traditions have the concept of the split from God or divinity. In the nondual perspectives, this split is understood to be a belief in separation from wholeness (Krishnamurti 1969) and characterizes what I would describe as my existential wound, which was accompanied by confusion and longing - the undercurrent upon which the swells of addiction and depression arose. In psychological terms, this might be viewed as the first or original attachment wound, and can be understood as the human predicament discussed in vast numbers of philosophies and religions and depicted in art, story, music and poetry.

This wound in myself is what led me into the inquiry into my essential Self or wholeness, and to discover the potential therapeutic benefits of this broader understanding of Self. From this perspective, this apparent separation is not from birth, but is psychologically developmental. It is not actual, but an acquired belief that occurs normally and naturally as we differentiate ourselves from our mothers and the world, and identify with our bodies and individual minds as we start seeing ourselves as existing inside the body and the 
world as existing outside the self/body. This lost connection with the true nature of Self can be understood as a natural consequence of being a manifest localized point of human perspective. (For more information on living organisms as dissociated alters of cosmic consciousness, surrounded by its thoughts, please see Kastrup 2018)

Spira (2017b) explains that as this natural separation process progresses, "the seed of the ego of a separate self that lies dormant in the infant, and that until now has been a process of individuation, begins to crystallize into a discrete entity, which identifies itself as the body-mind" (p. 38). He goes on to say that this gradual process of a child establishing their identity as a separate individual is a natural and essential part of development and would lead to psychological problems if not properly concluded. What can cause suffering later in life is not the child's natural process of individuation, but the conceptualization of herself as an entity living inside and as the body. In this model of development, ego as a process is replaced by ego as an entity, and in most cultures all further development is built upon the understanding of our self as that separate ego entity.

From this theoretical perspective, the deepening of this natural and developmental imagined split might occur through adverse early life experiences that reinforce this sense of separation and create an environment in which a child feels they must further identify with and then subsequently cut off parts of themselves to survive, and is in my view, the root of psychological suffering. The construction of a mental model of separate self, or ego, that must be constantly maintained, built up, and defended is the inevitable consequence of this split. Individual personhood and a functional sense of self in the world are necessary and healthy as a process, and a temporary identification with that process is natural. However, an enduring belief that one is contained within, and defined by that mental or psychological construction, as a separate self-entity, in this view, can result in insecurity and anxiety because that construct is inherently not secure, as the 'contents' (thoughts, perceptions, sensations, and feelings) that form and maintain it are continually changing. Due to our natural inclination toward that which is true to our nature, the tendency is to rid ourselves of this insecurity and anxiety by either building up this insecure self, or to rid ourselves of it through a myriad of coping behaviors, not limited to addictions and compulsions of all kinds.

A progression of the developmental differentiation process could include a felt sense of expanding beyond identification with body and mental processes (Spira 2017b) as we see through the objects of sensations, perceptions, feelings and thoughts to that which senses, perceives, feels and thinks; and further, toward simply sensing, perceiving, feeling and thinking and the simple knowing or awareness of these experiences. We can 'have' and use an ego construct, but as Wilber (1998) explains, "one is no longer exclusively identified with that self" (p. 31). We can experience and understand that construct as a process within awareness and not as an entity or self.

The extent to which the perceived existential separation or split is reinforced through rejection, shaming, neglect, injustice, abuse or other psychological harm in our early environment is the extent to which we suffer. This suffering can be lessened and eventually alleviated as awareness is brought to the misunderstanding of this perceived separation. Similarly, the extent to which caregivers of children are aware of their own wholeness or Self energy and bring those qualities of Self, such as presence, clarity, openness and love to developing children, is the extent to which those children recognize their innate wholeness of Self and its qualities. I have come to see that when our childhood environment, our caregivers or our communities, perpetuate a sense of separation (both their own and their child's) through the pathways of lack (deficiency or incompleteness) and fear (of abandonment, death, and rejection), this leads to a deepening sense of separation from the world and a further identification with and fragmentation of the psyche, as described by Schwartz and Sweezy (2020) Internal Family Systems model. When caregivers (or counselors) bring to the child (or client) their own Self energy and know themselves and others as whole in reality, embodying the qualities of true security, love, effortless compassion, openness, and allowing, they implicitly and explicitly foster the child's innate 
sense of wholeness. Children in this type of environment grow to see the shared beingness with others and the world, which profoundly impacts their experience of life and influences their interactions and relationships with the world and others. Their Self is leading them internally and externally.

This is the broader existential context that was missing for me in my therapy and that in later therapy helped bring a universal and timeless understanding and meaning of life for me. This understanding brought my psychology into context in a way that greatly supported my therapeutic work. I have come to see that when we feel like we are coming apart, we are right on script, we are not doing it wrong, it is deeply and utterly human. It is the cut from the source of ourselves that happens to us all in millions of unique ways. Some of us have had life experiences that have made that cut deeper, but that is not a problem. Whether it is a hairline fracture or a canyon, it is still only an apparent separation. It is not any harder to close an imaginary fracture than it is to close an imaginary chasm, as there is not anything in actuality to close. Healing, from this perspective, is whichever path and however much time it takes for the mind and body to catch up to this truth. Those with the imaginary chasms might take longer to see, and more importantly, feel this truth than those with subtle fissures, and may need more support and perhaps multiple pathways to this felt understanding. Approached from the understanding of wholeness, just like the labyrinth's path to center, all roads are the one path home.

\subsubsection{The Nondual Vedantic Inward-Facing Path and the Nature of Self}

The nondual wisdom that is discussed in these sections is based on the direct path of self-knowledge of Advaita Vedanta or the inward-facing path and the aspects of Kashmir Shaivism called the outward-facing or Tantric Path imparted by Rupert Spira (2014). See Appendix B for further information on Kashmir Shaivism and Advaita Vedanta.

The inward-facing path taught by Rupert Spira is rooted in the Vedantic tradition of the Direct Method or Path advocated by modern spiritual teachers such as Nisargadatta Maharaj [1973] (2012), Ramana Maharshi ([1948] 2008) and Atmananda Krishna Menon (Pillai 2019; Atmananda Krishna Menon 2009), in which the mind turns its attention away from objective experience towards its own essence or reality (Spira 2016a, 2016b, 2017a, 2017b). It is 'direct' because it does not require years of preparation, study, meditation, practices, or purification of the mind or body to recognize the essence or reality of the Self (Spira 2016c). The direct path does not imply any particular amount of time; much like a direct flight, there are no diversions or plane changes, but the amount of time it takes to get from one 'destination' to another depends on how far one seemingly is from the destination when the journey commences. Again, like the labyrinth, there is only one path, but it could be windy, turn back on itself, or be long or short. In this regard, ultimately, there is no wrong way to go.

Advaita means 'not two' in Sanskrit (ad-vaita) or nondual, which is to say that absolute reality and the world of appearances, or the relative world, are 'not two' (Spira 2017b). From this perspective, in reality, there are no subjects and objects, "much as a mirror and its reflections are not separate, or an ocean is one with its many waves" (Wilber 1998, p. 12). The fundamental truth of reality is whole. The Vedas are the sacred scriptures of India and 'Vedanta' is translated as the "end of the Vedas' or the last teaching (Spira 2017b). It is the last place the individual mind can go, the 'last stop' before Self recognition, which in this understanding is considered 'beyond' the finite or limited mind. Advaita inward contemplation is the turning of the attention away from the contents of objective experience (thoughts, feelings, perceptions, sensations) toward the source from which it has arisen. It is in this giving up or turning around that we cease being preoccupied with our suffering and gradually become more interested in the nature of the one who suffers.

This curiosity toward that with which experience is known, leads to self-inquiry and an understanding of our essential Self: pure objectless awareness (Spira 2017a). In the Direct Path, simple awareness is both the path and the goal, or as Spira (2017a) explains, "Being aware is simultaneously the subject that knows, the process of knowing and the 
object that is known" (p. 66). As the inquiry deepens by exploring the nature of awareness (limitless and timeless and, therefore, not divided), the relative qualities of love, peace, clarity, and intelligence or wisdom move from the background to the foreground of relative experience. Through a process of self-inquiry in which we investigate our immediate experience to verify what is not essential to our Being (through a process called in Sanskrit net neti-'not this, not that') and to verify what is true about the nature of Being (asking inner questions, such as "Can anything be experienced outside of awareness?'), we often come to see that we have mistakenly identified ourselves, our Being, with the limits and destiny of the body. We can also then begin to recognize our true nature as the transcendent Self, unlimited (without form) and ever present.

\subsubsection{The Outward-Facing Tantric Path: Healing from and Aligning with Self}

In Being Aware of Being Aware (Spira 2017a), Spira explains that the inward-facing path is only, at best, half the journey. Once we recognize in our direct experience the essence of the irreducible nature of the Self it is necessary to face 'outwards' again-toward objective experience, the world and relationships-facing any feelings of separation (fear and lack), becoming aware of behavior, thoughts, and feelings that arise from this belief of separation, and "realigning the way we think and feel, and subsequently act, perceive and relate, with our new understanding" of our wholeness (Spira 2017a, p. 10). Knowing one's essential self as the transcendent nature of awareness, through direct experience, without sensing and understanding its immanence - that this awareness pervades all knowledge and experience - can lead to what Spira calls "a fragile alliance" between our essential nature and all objects and others, "manifesting as denial or rejection of embodied life in the world" (Spira 2017a, p. 11). This may become a means through which a sense of further separation or fragmentation from life and the world manifests itself.

The transcendent nature of Self or aware presence is not dependent on qualia or phenomenal experience, as is evident in the experience of simply being aware of being aware; however, awareness is intrinsic to perceptions, sensations, and thoughts (Spira 2017a). If investigated in our experience, it becomes obvious that all that can be known can only be known through thinking, sensing and perceiving (Spira 2016c), which is only known by awareness. It follows that far from being separate from our essential nature as awareness, the world, others, and our bodies - anything that can be experienced-are made of awareness. The gap between subject and object is closed by welcoming all experience, including intolerable feelings, into our Self without agenda, much in the way the Self befriends scared or protective parts in IFS, and brings those fragmented parts back into the Self. In this way, what previously felt separate from us integrates and dissolves into our Being. Through embodied awareness and closing the perceived gap between Self and the world, objective experience now shines with the light of awareness, rather than eclipsing the Self (Spira 2017b). Spira (2016c) describes this intimacy between Self and the world saying, "The world becomes my body." Yet, despite understanding ourselves and the world to be nondual—not in reality separate - the appearance of multiplicity and diversity remains. We live in apparent duality while knowing, and more importantly, feeling ourselves, others, and the world to be one, whole, our true Self.

\section{Nothing Lacking, Already Whole: Innate Psychological Health}

An important factor in this particular way of looking at the Self and healing, as seen from the IFS model and particularly from the nondual direct path, is that we are essentially whole and have access to well-being and psychological health now. What commonly obfuscates this truth is attention to and sole identification with mutable experience, whether it is appearances in the outside world or an overlay of mental, emotional and psychological patterns (IFS parts and their burdens) added to our already whole and innate well-being. The result is the appearance of fragmentation, polarization and brokenness, and the accompanying pain of a sense of separation. In essence, these parts are created as a result of not fully knowing our wholeness (frequently as a result of our early separation-promoting 
experiences) and then these parts create further fragmentation that reinforces this feeling in a self-perpetuating system. The view that well-being is innate and undamaged by our experiences is somewhat of an expansion on Humanistic psychology, whereby a person is seen to have the capacity to overcome problems, make free choices, and actualize themselves (APA Dictionary of Psychology n.d.). Instead of seeing these as pathways to wholeness, this perspective views these as the natural effects and expressions of knowing deeply that we are already whole. In other words, we overcome problems, make free choices and actualize ourselves, not to become whole, but as an expression of the wholeness that we already are.

IFS has as a main premise that human nature is essentially and already whole, and thus, is naturally inclined toward health and well-being. Schwartz and Sweezy (2020) compare the positive view of human nature, that is an important aspect of IFS therapy, with the more negative view in developmental psychology's attachment theory, which posits that our basic nature is a result of the parenting we receive during critical periods of early development (Bowlby 1988); if we did not receive 'good enough' parenting during these critical periods, we will "remain broken until we have some kind of corrective reparenting experience from a therapist or significant other" (Schwartz and Sweezy 2020, p. 49). In IFS, the relationship with the therapist in not meant to correct a deficiency in the client's early caretaker relationships in order to advance the client's development, but instead relies upon the relationship to help release the already fully developed and undamaged Self that can naturally regulate and nurture the parts, when they show up in our experience, just as we are equipped to do (Schwartz and Sweezy 2020). Through my own expanding understanding of my essential nature, I have come to see more deeply that the parts are not pathological or disordered, but come about as the intelligent system's way of bringing the person closer to the qualities of Self (safety, peace, fulfillment), albeit through ways that may have some destructive or painful results.

In The Deep Heart: Our Portal to Presence, Prendergast (2019), a therapist who uses a nondual approach in his practice, challenges the notion that we must work through layers of psychological conditioning before we can encounter what is essential to us: "There are no preconditions for experiencing our true nature, the true nature that is always available as the background awareness to and core of every experience" (Prendergast 2019, p. 28). For this reason, glimpses of our essential Self can happen at any moment. In this way, the Self is not 'becoming' nor is it attained, created or developed, but is always present and is an expansion of and includes, but is not limited to, the ego process and all other aspects and parts. There is nothing to do to discover the Self other than notice the presence of ourselves, which lies beneath the coloring of experience that often focuses our attention on the overlays of our conditioned patterns within our experience.

We can trace our way back to the source of those patterns through various therapeutic or contemplative means. Once even the barest glimpse of our essential Self is recognized, various psychotherapeutic approaches can be undertaken to help heal those other aspects of ourselves that need transformation, while the process is being led and informed by Self. During this process, the client can start to recognize that these protective aspects (the Managers in IFS) are tasked with protecting, and thus maintaining, a sense of a self-entity, that in reality is a process (involving thought, feelings, sensations, images, memory, etc.) that has been identified with. These therapeutic approaches can include depth therapy, parts work, somatic work, expressive arts, or any other therapy that is appropriate for that particular individual. In essence, therapy involves the Self guiding the various aspects of the mind/psyche and body to catch up with what the Self already knows - that we are already whole, but for the thoughts and feelings that arise on behalf of the misunderstanding and belief that we are not.

\subsection{Glimpses Beyond the Limits of the Acquired Self: A Deeper Look at Self}

The Transpersonal Self goes by many names: Soul, Great Heart, Presence, Atman, Wholeness, True Nature, Higher Power, Authentic Self, Wise Self, Unconditioned or Uni- 
versal Mind. From the perspective of nondual wisdom, the Self or true nature is you at your most essential. However, what is that exactly? When posed with the question, 'who are you?' one will often describe the very surface layers of identification that might include autobiographical, cultural, racial, or relational information about ourselves, or we describe our personal traits, preferences, habits, mood tendencies, physical or mental characteristics. Some of these qualities are genealogical or biological, but mostly, these are acquired traits that we might call the biographical self-the aspects of ourselves conditioned through experience and cultural contexts. We often describe not so much 'who' but 'what we are like.' In other words, we describe relative and mutable qualities and identifications in the presence of a changing environmental context within a framework of time and space.

By focusing on the recognition and uncovering of the transpersonal Self, the intention is not to minimize or disregard personal, cultural, biographical or historical identities-all of these give our experience of self a richness and depth — but rather to temporarily shift focus to the background of these shifting identifications to better connect with our ground of Being. Who is it that is reading and understanding these words right now? Without referring to memory, including learned concepts, transient states of mind, feelings or projections of the future, how would you describe yourself? In other words, we are not asking what it feels like to be you and not what you think about you, but what is left after everything that is not essential to you is 'removed', so-to-speak. These are the questions asked and the answers discovered through the direct experience of the individual in the direct path of nondual understanding.

Through considering these questions and searching for the answers in our direct experience, we find that our 'beingness' or awareness seems to be self-evident by the very fact that the question, 'who are you?' can even be heard, understood, and reflected upon. That which hears, understands and reflects is who we are at our most essential. We seem to be present and aware even as the question is asked, before 'thought' searches for the answer. In Presence: Volume I, Rupert Spira (2016a) states simply, "I may not know what I am, but I know that I am" (p. 3). The knowledge "I am" seems to be a human given, albeit an overlooked one. From the nondual perspective, Spira (2016b) establishes the primacy of the presence and awareness as the true Self, and often refers to the Self as the presence of awareness. When we say "I feel sad", or "I am tired" it is that which is aware of these experiences that is what we refer to as "I". Our Self, presence or awareness is "the most intimate fact of experience" (Spira 2016b, p. 2). It is simply the knowing of our own Being and is the "primal and essential ingredient of experience", (p. 2) which makes all experience possible and knowable.

In IFS parts therapy, the Self is who we are independent of the development of and occlusion by the parts. The parts of the psyche that came into experience through adaptation to our environment are added to who we are essentially. Schwartz and Sweezy (2020) describe the dual nature of Self as either an active inner leader or an expansive boundaryless state of mind, likening it to the duality of light in quantum physics, whereby photons sometimes act like particles and sometimes like waves. Unlike the nondual traditions that generally see the Self or aware presence not as an entity, object or thing, the IFS perspective views the Self (like the quantum particle) as an aspect that can behave like an entity, available to interact with the parts to hear perspectives, to problem solve and to nurture, but (like a wave) is also transcendent and at one with the universe. In IFS, one can attain a shift in identification with the burdened parts to an understanding of oneself as the essence of Self or Being, which is what most spiritual traditions call enlightenment (Schwartz and Sweezy 2020).

\subsection{The Qualities of Self: Recognizing Self Essence}

The healing properties of the Self are known through one's relative experience in various ways that can become easily recognizable. According to Prendergast (in Prendergast et al. 2003), the Self is presence and can be described as Being that is aware of its own aware presence, and describes the effects a transcendent Self has on others as 
contagious: "When we are in the Presence of an individual who has awakened from the dream of 'me' [the ego], we can sense an unpretentiousness, lucidity, transparency, joy and ease of being" (p. 5). From the nondual understanding of the transpersonal Self as Awareness, the Self is objectless; that is, it is aware of objects but is not itself an object; it is noumenal and not phenomenal (Lucille 2006).

Awareness is known as a lack of disturbance, which is felt in the relative sense as peace; an absence of resistance, that is, therefore, inherently allowing; and as wholeness, lacking nothing, and is therefore felt as happiness, contentment or fulfillment. Another way of describing Awareness is as the absence of qualities stemming from separation (rooted in lack, conflict and fear), and described in their positive, they are happiness, peace, love, and openness (Spira 2016b). When we know ourselves as Awareness, we experience this relatively as clarity, understanding, wisdom, compassion, and true security; we feel safe in all our experience. This is not to say that we do not feel sadness, loss, or anger, but these feelings tend to have a different quality in the allowing and peaceful presence of Awareness. They do not arise on behalf of securing the insecure separate self. There is an absence of feeling like the sadness or anger is harming or taking something away from us and they find their proper expression and positive action, if needed, from a place of clarity.

From the IFS perspective, Self is the seat of consciousness and its qualities include those of a good leader: compassion, creativity, perspective, curiosity, confidence, and acceptance (Schwartz and Sweezy 2020). Kelly (Schwartz and Kelly 2018) describes the 11 'i's' of Self Essence as invisible, intelligent, innate, is, indestructible, infinite, impersonal, immediate, illumined, ineffable, and inspired. Self Essence does not change or grow, it just is. Self Essence cannot be hurt or destroyed and is "the authentic fundamental nature of who you are, which is felt as an awake awareness" (Schwartz and Kelly 2018). According to Schwartz and Sweezy (2020), a client whose parts are willing to differentiate, or separate out from the Self, describe feeling calm, light, centered and a sense of well-being and exhibit confidence and demonstrate openheartedness. These are the qualities that are needed for strong Self leadership.

\subsection{Who Knows the Self?}

In the ordinary meaning of the word, self is usually equivalent to the ego (which, according to Schwartz, is a collection of manager parts); however, in this discussion, the Self is more akin to Jung's Self archetype, which is "paradoxically not oneself" (Stein 1998, p. 152) and is closer in connotation to the Indian Upanishads designation of the higher personality or atman and is symbolic of unity or wholeness (Stein 1998). However, according to Jung, this wholeness is not completely achievable, since "the polarities and opposites resident in the self are forever generating more and new material" (in Stein 1998, p. 158). I agree with this only if one is identified with the polarities and parts within the psychological system. The ego will never know the Self because it is defined as not being the ego or more accurately, the ego is split from the Self and therefore seemingly not it. If we know ourselves only as a collection of self-concepts and images, the Self will be eclipsed. Only Self can know the Self. Wholeness only knows wholeness.

As Klein (2006) explains, "The ego cannot 'know' itself because it identifies with what it thinks, feels, experiences" (p. 9). By 'know itself' what is meant is the nature of itself or the essence of itself, i.e., the Self. In my own experience, the discovery that I am not limited to the objects in my experience resulted in the subtle and ordinary recognition of Self, dissolving the apparent ego or self-concept. According to Schwartz and Sweezy (2020), the parts do get to know the Self, but I would like to offer a slightly different perspective from my own experience through my nondual understanding and my work with IFS. I noticed that the parts do not really 'know' the Self, but rather begin to know themselves as the Self (not separate from the whole). As the Self permeates the parts with its aware light, it appears that the parts are 'knowing' the Self, but what is really happening is that the parts are transforming into knowing (awareness), or into the Self. Or the Self is turning the parts into itself. Upon fully integrating, it becomes obvious that the parts never existed 
apart from the Self at all. As the nondual 12-step recovery advocate, Paul Hedderman, depicts so accurately, instead of trying to add more paint to the canvas, "...something's going to bleed out from the other side .... You're going to know on the level of Being" (Hedderman 2019, p. 6). The knowing light shines through, turning what cannot know into knowing itself. What I did not realize throughout most of my therapy was that the very search for myself from the point of view of what I conceived of myself was what was perpetuating the seeming separation from Self and in fact reaffirmed that something was missing and needed to be supplied from outside of myself ('myself' in this case, the ego, collective parts, psyche or finite mind). The search was adding more paint to the canvas creating a thick cover that was obscuring the fact that something else was bleeding through from the other side. The self-luminating light of awareness.

\section{Essentially Whole, Relatively Wounded: Parts and the Separate Self}

Although we all have access to our essential Self at all times, this does not mean that we do not also have other psychological aspects that are in our experience. We experience the effects of patterns of psychological, mental and emotional activity, seen collectively, in some nondual traditions, as the conditioned mind, separate self, or ego states. In IFS these show up in our experience as Exiles, Managers and Firefighter parts that 'take over' the system and seem to cut off from or obscure the Self. In the nondual understanding, much of what we experience is conditioned mental, emotional and sensory/feeling patterns that revolve around a core belief that the self is a fragment, separate from the world and others and in need of defense and aggrandizement.

It might be helpful to see the Self aspect as the vertical formless dimension outside of time and space (in ever-present now) and the psychological aspects evolving on the horizontal, temporal, developmental plane through which our psychological experiences unfold. Nondual Awareness adds a depth dimension to any of the existing schools of psychology and can positively influence therapy through psychotherapists' own Self awareness. While the concept of nondual awareness has already been incorporated horizontally into the Transpersonal Psychology framework, its main effect occurs 'vertically' as therapists deepen their intimacy with Self (Prendergast et al. 2003). Both IFS and spiritual nondual therapeutic modalities bring this vertical dimension of wholeness to the client's awareness as the basis for further psychotherapeutic work, orienting the client toward their wholeness and bringing that essential wholeness to their relatively wounded and fragmented parts.

\subsection{The Missing Self: Identifying with the System in IFS}

One might ask, if we are essentially always whole and therefore naturally at peace and fulfilled, why is this not experienced by everyone in every moment? In the IFS model, one reason clients sometimes cannot find or sense Self is not from a lack of desire or ability, but because Self is not an "it" and is therefore often overlooked. Self is not an object that can be seen, heard, touched, smelled, tasted or known by thought. It is not an emotion, image, belief, thought, sensation, or even energy. "Trying to know Self with thought is like using our eyes to try to hear music" (Schwartz and Kelly 2018). The parts (often with extreme feelings or perspectives) overshadow the Self, especially if trauma or abuse was experienced. The parts become blended with the Self, an experience in which a part takes over a person's seat of consciousness (Self), which occurs "along a continuum so that the Self can remain present with some blending or be obscured completely with full blending" (Schwartz and Sweezy 2020, p. 281). In trauma-related responses, a part might hijack the body and completely obscure the Self (Fisher 2017) to such an extent that the only perspective available is that of a scared part. If Self is obscured and the parts are polarized, the inner life can be very conflictual and confusing, sometimes bordering on chaos. I came to see my own polarized parts as a kind of "autoimmune self", where parts of me attacked other parts they thought should not be there; the parts not recognizing that they are all part of the same whole. All of this inner conflict arises to defend or subdue something that does 
not exist apart from the activity that sustains it. Like the quiet and still eye of the storm, the self that is being protected or exiled is a memory, made of the same wind and rain of mental and emotional activity that created it, and when the storm settles down, all that is left is the eye or "I" of Self.

\section{Overlooking True Nature or the Veiling of Awareness}

The knowing of ourselves as aware presence is so simple and obvious, and so apparently insignificant that it is usually overlooked or not noticed. Who is it that fails to notice? Spira (2016b) explains that the Self cannot fail to know itself, just as the sun cannot fail to illuminate itself: "It is only thought that imagines our Self is not known and that something else, like a body, mind or world, is known" (p. 5). With this thought, our Self appears to contract inside the body and mind, and as a result, "intimacy is veiled, love is lost and seeking begins" (p. 5). The Self still knows only the intimacy of our Being, so it is only from the perspective of thought, or the inside "separate self," and never from the true Self, that this veiling occurs.

From this perspective, the overlooking and forgetting of our most intimate Being initiate almost all our thoughts, feelings, activities and relationships and turn out to be the source of unhappiness. However, it is not our Being that overlooks itself-our Being is who we are, not something we do; it is obscuring thought substantiated by feelings that results in the veiling or loss of the knowing of our Self as it truly is and makes it seem that our Self is something other than the presence of Awareness. Spira (2016a) proclaims that "the history of humanity, on both the individual and the collective scales, is the drama of this loss of our true identity and the subsequent search to regain it" (p. 5).

In addition, a belief forms that our Being resides in, is made of, and is limited to the body and mind. This belief is divided in two parts: a separate inside subject—the self that knows, feels or perceives - and a separate outside object, other or world that is known, felt or perceived. The belief that aware presence is synonymous with and limited to the body and shares its characteristics is responsible for the veiling or forgetting of our true identity of infinite aware presence. This veiling is a powerful illusion, an illusion that gives rise to the belief in an inside separate self and is the root of many more beliefs that are examined in the inward-facing path (Spira 2017a). The consequences of the veiling of our true presence by the belief in a separate, limited, fragmented self, is the cause of all internal suffering and outer conflict in the world.

\subsection{A Combined IFS/Nondual Interpretation of the Overlooking Self}

My nondual understanding informs my view of this veiling of Self through IFS work and I have a somewhat different view through my work with both. In IFS, rather than the protective managers preserving the Self (wholeness) per se, the protectors are protecting the exiles - those parts deemed unworthy, unsafe, or dangerous by the finite (personal) mind-which, constitute the "separate self" activity, based on the belief in an illusion of separation. These parts are the result of identifying with traits, or patterns of thought and feeling, judged by the system/mind as dangerous, on some level, to survival.

From a nondual perspective, these parts would be considered resistance or aversion, often compounded by failures of safety in the family or environment. These parts are 'exiled' or seemingly separated from the whole Self and contribute to the felt sense of and belief in separation as well as the resulting sense of insecurity that veils the light of Self Awareness, our essential Self. The protectors/Managers (in nonduality, insecure and fearful thoughts and resulting behaviors) operate on behalf of these exiles or sense of a separate self. In reaction to the insecurity or fear that arises, Managers also try to build up, secure, or maintain this separate insecure self. All of this activity results in the further obscuring or veiling of the Self, which Schwartz and Sweezy (2020) describe as the 'pushing out' of Self by protectors, and maintaining the 'system'. 


\subsection{The Importance of Contacting and Accessing the Self Early in Therapy}

From my own experience and personal observations as well as conversations with people who have founds limits to healing in conventional psychotherapy, the contribution of identifying and having a felt understanding of the essential Self is vast, immediate, and can greatly facilitate the therapeutic process; softening defenses and saving often months or years of ruminating and getting stuck in egoic stories. The recognition of Self as the presence of awareness expands the vertical dimension into the ideas presented by IFS or other therapies that have a plural mind perspective by exploring the creation of an apparent separate self, constructed by identifying with thoughts and feelings that have a root in aversion and lack (seeking and resisting). The interpretation of and subsequent identification with the seeking/resisting thoughts and feelings lead to what IFS would call exiled parts that constitute the felt sense of separation or fragmentation and contributes to the overshadowing or the veiling of Self.

I believe that this expanded view of IFS therapy brings the psychological aspects into a broader context beyond the study of the psyche. This investigative and contemplative approach coupled with the embodied and intimate tantric practices offer an alternative for those who do not want to, or cannot, do IFS parts therapy in the current model. The implications of this feeling-based understanding have profound effects on how we act, behave, and see the world, ourselves and others, and it liberates energy for creative action. From this view, the consequences of failing to bring the Self into the light of awareness is further polarization, the proliferation of fragmented parts, inner and outer conflict, and a deepening sense of separation, loneliness, and alienation from Self, life, and the world.

Innate Wholeness: Why it Matters

Many, but not all, therapies are based on concepts of pathology, correcting personality deficits or fixing problematic aspects of a person's thinking, and supplying missing experiences often with the goal of helping them cope or restoring functionality in a society that is, quite often, dysfunctional. Some are indeed geared toward these goals with the underlying assumption that 'something is wrong' and needs to be corrected, developed or supplied. To be clear, when a person comes to therapy they are often not functioning well and lots of things appear dysfunctional. The 'already whole' perspective is not suggesting that nothing should change, rather it rests very deeply on the humanistic understanding that the qualities and resources one needs are readily available at all times. This is not to say that skills do not need to be learned, new ways of communicating or behaving are not acquired, patterns changed, and mental, emotional and behavioral habits reconditioned, but the client relies on their innate wisdom to guide them to the resources they need and their intuition about what they need when options are available. Self-guidance in healing IS the healing: Wholeness takes the hand of what is broken and leads her back to the wholeness of Self.

In this way, clients come to see that they have always had these resources and that the ways their system protects them comes from a deep intelligence and love of Self. This is not trying to convince a client to love parts of themselves that they do not (or that other 'parts' do not) or 'seeing what is good' in all the bad-it is seeing that they have always been operating perfectly based on a certain perspective or understanding (through the point of view of child parts or the separate self or ego). Their entire Self is designed to lead them back to themselves, back to their essential Self and their innate qualities. Their Self has been hiding in plain sight and they only need to 'get eyes for it' to see what has always been true. This understanding and Self-attunement brings a relaxing of defensive parts as the presence of Self is felt and known. This allows for the deeper layers of feelings to show up and for the client to feel safe. I see this as a paradigm shift, a reorientation that has the power to change the experience of the mental maze into one of a labyrinth of liberation. 


\section{Conclusions}

This inquiry has led me to the conviction that the Self is the center of healing in any therapeutic model or modality, whether it is acknowledged as such, called by another name, or conceived differently, such as a 'capacity to heal' or a quest for wholeness, inner wisdom, or even referred to as the biological effects, such as 'rewiring the brain.' Both IFS and the nondual wisdom traditions hold that the wholeness of the transpersonal Self is self-evident, inherently undamaged, can be accessed readily with willingness and openness, and selfhealing. This understanding of Self naturally moves us in the direction of remedying inner and outer injustice with love and openness and is the ultimate presence for attachment for the inner parts and outer relationships (Schwartz and Sweezy 2020).

Nondual wisdom points us to the original wound of the apparent splitting off from the fabric of wholeness, the flow of life, and the shared beingness with everything and everyone. With an ever deepening and never-ending exploration we find that as we are not separate from the world, and that while bodies can be hurt, become sick or injured and eventually die, and finite minds are limited, we know and feel ourselves as not two, not separate, and in this way, we come to know that there is not me and other, us and them, or me against the world; and ultimately, as such, we are ultimately safe everywhere.

This kind of healing is not limited to personal psychological or spiritual healing and does not just affect the client and her immediate relationships. Coming to know the Self as the ground of being through self-inquiry, unburdening the parts, or any other means, allows the activity of mind or ego to drop off or dissipate, allowing the Self's qualities of clarity and courage to radically shift our perspective (Schwartz and Sweezy 2020). As Schwartz says, "Having been released from the optical delusion that we are all separate, we see injustice clearly, we fear for our environment, and we are oriented to take action" (Schwartz and Sweezy 2020, p. 54). We become less ego-centric and more "socio- and species-centric, bio-and earth-centric" (Schwartz and Sweezy 2020, p. 54) from having a clear awareness of our interconnectedness. Self-led action and communication tends to be more effective in the world because such qualities as compassion, clarity and calm often touch the Self in others, whereas action from polarized parts (power-seeking, righteousness, or caretaking) conflict with one another and lead to burnout and cynicism in the long-run.

With the Self leading the way, we find that the awareness of our interconnectedness leads to social and environmental action, according to our individual resources and abilities (Schwartz and Sweezy 2020). With our deepening knowledge of our Self and openness to all parts that arise, we find that our actions, thoughts, feelings and relationships no longer serve the demands of an insecure separate self. Rather our inner and outer lives align with our felt knowledge of shared being and carry with them a universal clarity and power that guides us and includes all. With the consistent felt understanding of the collapse of self and other into one and the recognition that our ground of being is love, our unburdened individual selves are energized and free to act in ways consistent with that love for all beings, in manners that are uniquely suited to each individual.

Throughout my life, I sought healing, wholeness, fulfillment, and happiness in many directions both spiritual and psychological, but it always felt like I was terrifyingly walking a tightrope 1000 miles above the ground, and with each spiritual practice or therapy intervention, I was thrown a tether or sometimes just a thread. I would hang on to it as long as I could, feeling temporarily less wobbly and more secure, but would eventually drop it or it would fray and I would be left on my own, balancing on a tightrope, impossibly high from the ground. It was not until I truly felt my spiritual essence/true nature, the internal golden thread, that in one eternal moment, I saw with utmost clarity that I had always and only ever been just inches from the ground - and in that instant, I simply stepped off the tightrope into the infinite ground of Being. I have been here ever since and this is the ground upon which I open myself to life and to others.

Funding: This research received no external funding.

Conflicts of Interest: The author declares no conflict of interest. 


\section{Appendix A}

Definitions and Terms

- $\quad$ (The capital 'S') Self: transpersonal or essential Self.

- In a general sense, I am using the definition of transpersonal found in the APA Dictionary of Psychology within the definition of 'transpersonal psychology': Transpersonal refers to the concern with ends that transcend personal identity and individual, immediate desires (APA Dictionary of Psychology n.d.). I am speaking of that which goes beyond the beliefs of what we think or conceptualize as ourselves as well as the felt sense of those beliefs and self-concepts.

- I use the words wholeness, true nature, awareness and Self synonymously to represent the essential Self.

- Essential Self: Whatever it is that knows or is aware of all experience and does not appear and disappear in experience.

- Functional self: Ego, or sense of localization that gives rise to agency, personal will, autonomy, and identification with a limited body and finite mind.

- The system (in IFS): The organization or the process of mental and emotional processing, meaning making, interpretation, belief making. In parts language, they are exiles, managers, firefighters (Schwartz and Sweezy 2020).

- Psyche/mind: The activity of mind in its totality, including all types of thinking, imagining, and conceptualizing and the internal logic of this mental processing. I use the words 'psyche' and "mind" interchangeably and sometimes use it to mean 'the system.'

- Ego: The self, particularly the conscious sense of self (Latin, "I"). In its popular and quasi-technical sense, ego refers to all the psychological phenomena and processes that are related to the self and that comprise the individual's attitudes, values, and concerns (APA Dictionary of Psychology n.d.)[with which one identifies with].

- Separate self: An activity of thinking, feeling, acting, perceiving and relating on behalf of an imagined, temporary, finite consciousness.

- Object: Anything that can be known: thoughts, feelings, perceptions, sensations. (Also: objects of experience: all that we are aware of.)

- Perceiving: to become aware of through the senses (Merriam-Webster.com Dictionary n.d., accessed on 3 September 2021).

- Psychological self: A subject or personal identification with the system of psychological processes, defenses, and various mental processes. Acquired self: Autobiographical self, based on history, memory, preferences and dislikes, based on experience, learning, conditioning and psychological patterning.

- Illusion: A real object of experience, the reality of which is not what it appears to be.

\section{Appendix B}

Resources and Further Reading

Internal Family Systems: https: / ifs-institute.com/ (accessed on 2 September 2021). Rupert Spira: https://rupertspira.com/ (accessed on 2 September 2021). Francis Lucille: https:/ / francislucille.com/ (accessed on 2 September 2021). Kashmir Shaivism: https:/ /iep.utm.edu/kashmiri/ (accessed on 2 September 2021).

\section{References}

APA Dictionary of Psychology. n.d.a. Transpersonal Psychology. Available online: https://dictionary.apa.org/transpersonalpsychology (accessed on 22 June 2020).

APA Dictionary of Psychology. n.d.b. Humanistic Psychology. Available online: https:/ / dictionary.apa.org/humanistic-psychology (accessed on 27 August 2020).

APA Dictionary of Psychology. n.d.c. Ego. Available online: https:/ / dictionary.apa.org/ego (accessed on 17 June 2020).

Atmananda Krishna Menon. 2009. Notes on Spiritual Discourses of Srīatmānanda, 2nd ed. Edited by Tripta Nitya. Salisbury: Non-Duality Press \& Stillness Speaks, vol. 1.

Bowlby, John. 1988. A Secure Base: Parent-Child Attachment and Healthy Human Development. New York: Basic Books. 
Brenner, Gail. 2018. Suffering Is Optional: A Spiritual Guide to Freedom from Self-Judgment E Feelings of Inadequacy. Oakland: Reveal Press. Daniels, Michael. 2002a. The Transpersonal Self: 1. A Psychohistory and Phenomenology of the Soul. Available online: http: //www.transpersonalscience.org/Papers/daniels02d.pdf (accessed on 28 August 2021).

Daniels, Michael. 2002b. The Transpersonal Self: 2. Comparing Seven Psychological Theories. Available online: https://psychicscience. org/Papers/daniels02b.pdf (accessed on 28 August 2021).

Fisher, Janina. 2017. Healing the Fragmented Selves of Trauma Survivors Overcoming Internal Self-Alienation. New York: Routledge Press-Taylor and Francis Group.

GreekMythology.com. 2021. Ariadne. GreekMythology.com Website. Available online: https://www.greekmythology.com/Myths / Mortals/Ariadne/ariadne.html (accessed on 21 July 2020).

Hedderman, Paul. 2019. The Incomplete Works of Paul Hedderman, Volume I: On Having Never Left. Independently Published.

Jung, C. G. 1970. The Collected Works of C.G. Jung. Princeton: Princeton University Press, vol. 17. First published 1954.

Kastrup, Bernardo. 2018. The universe in consciousness. Journal of Consciousness Studies 25: 125-155.

Kingsley, Jenny. 2010. Musing and meandering through labyrinths and mazes. The Art Book 17: 90-92. [CrossRef]

Klein, Jean. 2006. I am. Edited by Emma Edwards. Oakland: Non-Duality Press.

Krishnamurti, J. 1969. Freedom from the Known. Edited by Mary Lutyens. London: Gollancz.

Life, David. 2007. See More Clearly by Practicing Drishti. Available online: https:/ /www.yogajournal.com/yoga-101/philosophy/theeye-of-the-beholder (accessed on 28 August 2007).

Lucille, Francis. 2006. The Perfume of Silence. Temecula: Truespeech Productions.

Nisargadatta Maharaj. 2012. I Am That: Talks with Sri Nisargadatta Maharaj. Edited by Sudhakar S. Dikshit. Translated by Maurice Frydman. Durham: Acorn Press.

Maharshi, Ramana. 2008. Who am I?: The Teachings of Bhagavan Sri Ramana Maharshi. Tamil Nadu: Sri Ramanasramam.

Merriam-Webster.com Dictionary. n.d. Perceive. Available online: https://www.merriam-webster.com/dictionary/perceive (accessed on 3 September 2021).

Pillai, Narayana N. 2019. Atmananda Krishna Menon: Direct Path to Realization 'I'-Principle. Chattampi Swami Archive Project. Trivandrum: Centre for South Indian Studies.

Prendergast, John J., Peter Fenner, and Sheila Krystal. 2003. The Sacred Mirror: Nondual Wisdom E Psychotherapy. St. Paul: Paragon House. Prendergast, John J. 2019. The Deep Heart: Our Portal to Presence. Boulder: Sounds True.

Schwartz, Richard C., and Robert Falconer. 2017. Many Minds, One Self: Evidence for a Radical Shift in Paradigm. Oak Park: Trailheads.

Schwartz, Richard C., and Loch Kelly. 2018. Accessing and Living from Self. IFS Institute online Course. Available online: http: / / courses.ifscircle.com/self/ (accessed on 11 November 2019).

Schwartz, Richard C., and Martha Sweezy. 2020. Internal Family Systems Therapy. New York: The Guilford Press.

Spira, Rupert. 2014. The Light of Pure Knowing: Thirty Meditations on the Essence of Non-Duality. Oxford: Sahaja Publications.

Spira, Rupert. 2016a. Presence, Volume I: The Art of Peace and Happiness. Oxford: Sahaja Publications.

Spira, Rupert. 2016b. Presence, Volume II: The Intimacy of all Experience. Oxford: Sahaja Publications.

Spira, Rupert. 2016c. Transparent Body, Luminous World: The Tantric Yoga of Sensation and Perception. Oxford: Sahaja Publications.

Spira, Rupert. 2017a. Being Aware of Being Aware. Oxford: Sahaja Publications.

Spira, Rupert. 2017b. The Nature of Consciousness. Oxford: Sahaja Publications.

Stein, Murray. 1998. Jung's Map of the Soul: An Introduction. Chicago: Open Court.

Welwood, John. 1983. Awakening the Heart: East/West Approaches to Psychotherapy and the Healing Relationship. Boston: Shambhala.

Weinberg, Gerald M. 2001. An Introduction to General Systems Thinking. New York: Dorset House Publishing.

Wilber, Ken. 1998. The Essential Ken Wilber: An Introductory Reader. Boston: Shambhala. 